\title{
Antimicrobial activity of puffball(Bovistella radicata) and separation of bioactive compounds
}

\author{
Yong Ye, Kun Liu, Qinghua Zeng and Qingmei Zeng*
}

\begin{abstract}
Background: To test the antimicrobial activity of different extracts and fermentation broth from puffball(Bovistella radicata), the different extracts and fermentation broth of puffball were prepared, the active fraction was investigated by UPLC-UV-MS and semi-preparative chromatograph.

Results: Through zones of inhibition (ZOI) and minimum inhibitory concentrations (MIC) tests, the supernatant of fermentation possessed best antimicrobial activity in all extracts whose MIC value is $31.2 \mu \mathrm{g} / \mathrm{ml}$ against T. rubrum, $T$. mentagrophytes, S. aureus and P. aeruginosa. And ZOI value is 29.01, 21.02, 35.02, $28.01 \mathrm{~mm}$ against T. rubrum, T. mentagrophytes, S. aureus and P. aeruginosa. Then we compare the puffball fermentation supernatant with blank contrast by LC-MS. There are the characteristic peaks named PBR-1 and PBR-2 with the puffball fermentation supernatant, the separation of compound PBR-1 and PBR-2 was done on semi-preparative C18 column and the MIC and ZOI of compound PBR-1 and PBR-2 are $15.6 \mu \mathrm{g} / \mathrm{ml}$ and $34 \mathrm{~mm}$ with the antifungal test.
\end{abstract}

Conclusions: The fermentation supernatant and compound PBR-1 and PBR-2 have promising antifungal activity against T. rubrum and T. mentagrophytes.

Keywords: Antimicrobial activity, Tinea pedis, Puffball, Fermentation supernatant, LC-MS

\section{Introduction}

Tinea pedis is common ailment, its treatment is a serious problem due to continuous drug resistance that microorganisms soon develop against antibiotic drugs (Subissi et al. 2010), great hope rests with traditional Chinese medicine as they contain different types of primary and secondary metabolites with antimicrobial pharmacophores (Zhang et al. 2011). Trichophyton rubrum ( $T$. rubrum) and Trichophyton mentagrophytes (T. mentagrophytes) are main tinea pedis pathogen (Koltin and Hitchcock 1997), Candida albicans (C. albicans) is opportunistic fungus pathogen (Cotter and Kavanagh 2000). S. aureus and $P$. aeruginosa are main tinea pedis pathogen of secondary infection (Erbagci et al. 2005), Due to the emergence of resistant pathogens and the side effects of antimicrobial agents, it becomes necessary to search for

*Correspondence: zengqingmei-1@163.com

School of Food Science and Engineering, Hefei University of Technology,

124 ShenHua Building, 193rd TunXi Road, Hefei 230009, Anhui, China new antibiotics (Cornaglia 2009). It is important to discover novel metabolites from natural resources and it is considered as an important research field.

Traditional Chinese medicine has been practiced for many centuries (Zuo et al. 2014, 2016; Xiao et al. 2016). Over the past few decades, numerous studies have been conducted on plants to explore possible candidates for antibiotic drugs. Extracts from traditional medicinal represent a continuous effort to find new compounds with the potential to act against multi-resistant microorganisms (Zampini et al. 2009). Owing to puffball diversity in biological activities and production of novel chemical compounds, it is well known that puffball's antibacterial activity is promising (Novakovic et al. 2015).

Puffball can be found in many provinces of china. Puffball was named as Bovistella radicata from Shuinan town, Jiangxi province in this test. The local people use it as a remedy for anti-tinea pedis and effect is significant. According to Chinese Pharmacopoeia, puffball has 
been reported to have a number of functions like antiinflammatory, stanch bleeding, cough, respiratory infections etc., however, we encountered limited published information related to antimicrobial effect of puffball, especially the antifungal activity of puffball has not been considered until now. Therefore, the present study was aimed to investigate the antimicrobial activity of puffball from Jiangxi province. In order to investigate its antimicrobial activity, main kinds of tinea pedis pathogen were selected. The antimicrobial tests were done. Isolation and identification of the activity component in puffball fermentation was done based on LC-MS. Contrast tests also demonstrated that the compound PBR-1 and PBR-2 in fermentation supernatant of puffball was active particularly against $T$. rubrum. We can make next step to indentify the structures of the compound PBR-1 and PBR-2 to develop new antibacterial substance with stronger antimicrobial activity and more beneficial characteristics.

\section{Materials and methods Chemicals and instruments}

Solvents used for extraction and fractionation including ethanol, chloroform, n-butanol, ethyl acetate, aether were of AR grade. All the above reagents and potato dextrose agar (PDA), glucose (Glc) and agar were purchased from Sinopharm Chemical Reagent Beijing Co., Ltd. Standard antibiotic drugs, gentamycin and terbinafine were obtained from Pharmagen, Hefei. Laminar flow cabinet was produced by Stramline Laboratory. Petri plates and glass columns were bought from Hefei Meifeng Chemical Instrument Co. Ltd. Autoclaver was produced by Shanghai ShenAn medical equipment factory.

\section{Microorganisms}

Antimicrobial microorganism (Bovistella radicata)

Sporophore and spore powder of puffball were obtained from pine forest of Shuinan town, Jishui county, Jiangxi province, China, with assistance of local traditional healers. After strain identification, it belongs to Agaricales order, Lycoperdaceae family, Bovistella genus, Bovistella radicata species, and authenticated by Professor Qingmei Zeng, College of Food Science and Engineering, Hefei University of Technology, China. Puffball(Bovistella radicata) specimen was dried and deposited at the herbarium of Department of Biology, Hefei University of Technology, China.

\section{Test microorganisms}

Test microorganisms were obtained from the Microbiology Laboratory at Department of Biology, Hefei University of Technology, Anhui. Eight strains of test microorganisms included four bacteria Staphylococcus aureus (ATCC 6538), Bacillus subtilis (ATCC 6051), Pseudomonas aeruginosa (ATCC 9027), Escherichia coli (ATCC 8739) and four fungi Trichophyton rubrum (ATCC 28188), Trichophyton mentagrophytes (ATCC 9533), Epidermophyton floccosum (ATCC 52066) and Candida albicans (ATCC 10231).

\section{Preparation of different extracts and fermentation from puffball}

After crushed and ground, the dried sporophore of puffball was mixed with spore powder. According to established protocols (Tian et al. 2011; Zhang et al. 2012; Sen et al. 2014), each $10 \mathrm{mg}$ mixed puffball powder were extracted by $200 \mathrm{ml}$ ethanol/aqueous/chloroform $/ \mathrm{n}$ butanol/Aether/Ethyl acetate for continuously $10 \mathrm{~h}$. After filtration over Whatman No. 4 paper, the extracts were concentrated under a reduced pressure at $40^{\circ} \mathrm{C}$ and stored at $4{ }^{\circ} \mathrm{C}$ in sterile bottles for further use.

\section{The concentrate supernatant of puffball fermentation}

The mixed powder of puffball was cultured in PDB (potato dextrose broth) at $25^{\circ} \mathrm{C}$ for 2 days, the fermentation was centrifuged at $7000 \mathrm{rpm}$ for $20 \mathrm{~min}$ to get the supernatant, the supernatant was filtered over Whatman No. 4 paper, then the filtrates were evaporated on rotary evaporator at low pressure to obtain $0.5 \mathrm{mg} / \mathrm{ml}$ concentrate supernatant, the $0.5 \mathrm{mg} / \mathrm{ml}$ concentration was prepared as stock solution for further use. From stock solution, multiple proportions dilutions were prepared in water of 500, 250, 125, 62.5, 31.2, 15.6 and $7.8 \mu \mathrm{g} / \mathrm{ml}$ concentrations.

\section{Assessment of antimicrobial activity}

The antimicrobial activity of puffball(Bovistella radicata) extracts was evaluated using two kinds of disk diffusion methods which were zones of inhibition (ZOI) (Geetha et al. 2015) and minimum inhibitory concentrations (MICs) (Negi et al. 2003), ZOI is qualitative analysis and MIC is quantitative analysis of antimicrobial activity (Dharajiya et al. 2015).

In this study, four bacterial strains and four fungal strains were used to determined the antimicrobial activity of puffball(Bovistella radicata). The agar cultures of $S$. aureus, B. subtilis, P. aeruginosa, E. coli were prepared to assess the puffball antibacterial effects. $50 \mathrm{ml}$ of nutrient broth medium poured into an erlenmeyer flask, four flasks were prepared for each examined samples. The flasks including agar medium were sterilized in an autoclave at $121^{\circ} \mathrm{C}$ for $15 \mathrm{~min}$. For antibacterial tests, bacterial cultures were grown at $35^{\circ} \mathrm{C}$ for $24 \mathrm{~h}$ by inoculation in Nutrient Broth (Hopper. 1992). Petri dishes with $20 \mathrm{ml}$ of Nutrient Agar were prepared, previously inoculated with $100 \mu \mathrm{l}$ of culture suspension (1\%, containing 
$10^{6}-10^{7} \mathrm{cfu} / \mathrm{ml}$ ) and same volume of deionised water was used as a control. Three wells $(5.0 \mathrm{~mm}$ in diameter) were cut from the agar at sterile condition. The prepared solutions of puffball were filled into the wells. The inoculated plates were incubated of $24 \mathrm{~h}$ at $35^{\circ} \mathrm{C}$, after which, it was observed for antimicrobial activity of the samples. At the end of the incubation period, the measurements were done basically from the edge of the zone to the edge of the well.

The same method was used for all the fungal samples. T. rubrum, T. mentagrophytes, E. floccosum and C. albicans were grown in Potato dextrose broth (PDB) at $25^{\circ} \mathrm{C}$ for $48 \mathrm{~h}$. $100 \mu \mathrm{l}$ different fungal strain cultures (1\%, containing $10^{6}-10^{7} \mathrm{cfu} / \mathrm{ml}$ ) were added to different flasks containing $25 \mathrm{ml}$ sterile PDA at $45{ }^{\circ} \mathrm{C}$ and poured into Petri dishes. The agar was allowed to solidify at $4{ }^{\circ} \mathrm{C}$ for $1 \mathrm{~h}$. The wells $(5.0 \mathrm{~mm}$ in diameter) were cut from the agar at sterile condition. The inoculated plates were incubated of $24 \mathrm{~h}$ at $25^{\circ} \mathrm{C}$. PDA plates added normal saline were used as controls. The plates were then incubated at $25{ }^{\circ} \mathrm{C}$ for 2 days. The zone of inhibition (ZOI) were calculated.

For the MIC determination of a sample, agar well dilution method (Bourdeau et al. 2004) was used. Potato dextrose agar (PDA) was dissolved in distilled water with concentration $38 \mathrm{~g} / \mathrm{l}$, and autoclaved at $121{ }^{\circ} \mathrm{C}$ for $0.5 \mathrm{~h}$. It was allowed to come to $50{ }^{\circ} \mathrm{C}$ before being poured into Petri plates for sample preparation. Different dilutions of each extract were prepared in this agar, with concentrations of the extract $(500,250,125,62.5,31.2,15.6$ and $7.8 \mu \mathrm{g} / \mathrm{ml}$ ). The content of each plate was mixed well and allowed to solidify. Stock solution of each extract/fraction was prepared and dilutions were made. Then, microbial cultures were transferred onto the content of each Petri plate with the help of a multipoint inoculator. Positive control and solvent control were also included. Plates were then incubated for $24 \mathrm{~h}$ at $37^{\circ} \mathrm{C}$, after which they were observed, the lowest concentration of antimicrobial agent at which there was no visible growth of a microorganism after incubation was taken as MIC (Petar et al. 2016) and MICs were noted.

\section{UPLC-UV-MS analysis of puffball}

The prepared solution of fermentation was also analyzed by ultra-performance liquid chromatography (UPLC) coupled with ultraviolet (UV) and Micromass-LCT Premier time of flight (TOF) mass spectrometer (Waters, MA, USA) detector. The aim was to identify the most active fractions in the compounds of puffball. A C18 reversed-phase column (Hypersil Gold $25 \mathrm{~mm} \times 2.1 \mathrm{~mm}$, $1.8 \mu \mathrm{m}$, Thermo Scientific, Massachusetts, USA) was used with the following solvent system: $\mathrm{A}=$ acetonitrile, $\mathrm{B}=0.15 \%$ ammonium acetate-water. The gradient elution was $7 \% \mathrm{~A}$ in $5 \mathrm{~min}, 7-10 \% \mathrm{~A}$ in $3 \mathrm{~min}, 10 \% \mathrm{~A}$ in $2 \mathrm{~min}, 10-15 \% \mathrm{~A}$ in $5 \mathrm{~min}, 15 \% \mathrm{~A}$ in $3 \mathrm{~min}, 15-5 \% \mathrm{~A}$ in $2 \mathrm{~min}$. The LC system operated at flow rate of $1.5 \mathrm{ml} / \mathrm{min}$ for $20 \mathrm{~min}$. The injection volume was $5 \mu \mathrm{l}$. The detection was at $330 \mathrm{~nm}$. The bioactive fractions were recorded on a HPLC-MS/MS system which consisted of the HPLC Premier XE (Waters, MA, USA) connected through a split to the mass spectrometer (Waters, MA, USA) detector system operating at $45{ }^{\circ} \mathrm{C}$. The MS analyses were performed using positive ion mode electrospray ionization mass spectrometry (ESI(+)-MS). The optimized system parameters were as follows: capillary voltage $3000 \mathrm{~V}$, sample cone $30 \mathrm{~V}$, source temperature $120{ }^{\circ} \mathrm{C}$, desolvation temperature of $300{ }^{\circ} \mathrm{C}$ and collision energy $4 \mathrm{~V}$, cone gas flow $70 \mathrm{l} / \mathrm{h}$ and desolvation gas flow of $350 \mathrm{l} / \mathrm{h}$. Detection was performed in positive ion mode in the $\mathrm{m} / \mathrm{z}$ range $50-1000$.

\section{Testify the antifungal activity of prepared compound PBR-1 and PBR-2 from puffball fermentation}

The separation was carried out on semi-preparative C18 column (Phenomenex). A stock solution of supernatant of puffball fermentation was prepared. Another stock solution of blank control (PDB medium) puffball sporophore was prepared as same steps.

We compared the antifungal activity of the compound PBR-1 and PBR-2 from puffball fermentation with blank control (retention time from 8 to $12.5 \mathrm{~min}$ ) by ZOI test, T. rubrum and T. mentagrophytes are main tinea pedis pathogens (Djeridane et al. 2006), so they were choosed as test microorganisms. T. rubrum and T. mentagrophytes were inoculated in a preliminarily melted and tempered to $45-48{ }^{\circ} \mathrm{C}$ PDA medium. The inoculated PDA media were transferred in quantity of $20 \mathrm{ml}$ in sterilized Petri dishes $(\mathrm{d}=9 \mathrm{~cm})$ and allowed to solidify. After this, three wells $(\mathrm{d}=6 \mathrm{~mm})$ per dish were cut. Then the separation compound PBR-1 and PBR-2 from puffball fermentation was added into three wells $(100 \mu \mathrm{l} /$ well $)$.

\section{Results}

In vitro antimicrobial assay

MIC values of prepared solution from puffball against fungi and bacteria are reported in Table 1 . The most polar extracts of puffball showed antibacterial and antifungal activity against most tested microorganism. Fermentation supernatant from puffball showed good activity against the tested microorganism and the strongest activity was seen against T. rubrum, T. mentagrophytes, $S$. aureus and P. aeruginosa (MIC $=31.2 \mu \mathrm{g} /$ $\mathrm{ml})$, In addition, B. subtilis resisted all prepared solution of puffball $(\mathrm{MIC} \geq 500 \mu \mathrm{g} / \mathrm{ml})$. Chloroform, aether and ethyl acetate extracts of puffball demonstrated very close activities against all microorganism, all microorganism 
Table 1 MIC values of fermentation supernatant and extracts of puffball

\begin{tabular}{|c|c|c|c|c|}
\hline \multirow[t]{3}{*}{ Extracts/fractions of puffball } & \multicolumn{4}{|c|}{$\mathrm{MIC}(\mu \mathrm{g} / \mathrm{ml})$} \\
\hline & \multicolumn{4}{|l|}{ Fungus } \\
\hline & T. rubrum & T. mentagrophytes & E. floccosum & C. albicans \\
\hline Fermentation supernatant & 31.2 & 31.2 & 62.5 & 125 \\
\hline Ethanol extract & 62.5 & 62.5 & 125 & 125 \\
\hline Chloroform extract & $>500$ & $>500$ & $>500$ & $>500$ \\
\hline Aqueous extract & 31.2 & 31.2 & 62.5 & 62.5 \\
\hline Ethyl acetate extract & $>500$ & $>500$ & $>500$ & $>500$ \\
\hline n-butanol extract & 62.5 & 31.2 & 62.5 & 62.5 \\
\hline Aether & $>500$ & $>500$ & $>500$ & $>500$ \\
\hline Terbinafine & 31.2 & 15.6 & 62.5 & 7.8 \\
\hline \multirow[t]{3}{*}{ Extracts/fractions of puffball } & \multicolumn{4}{|c|}{$\mathrm{MIC}(\mu \mathrm{g} / \mathrm{ml})$} \\
\hline & \multicolumn{4}{|l|}{ Bacteria } \\
\hline & B. subtilis & S. aureus & E. coli & P. aeruginosa \\
\hline Fermentation supernatant & 500 & 31.2 & 62.5 & 31.2 \\
\hline Ethanol extract & 500 & 62.5 & 125 & 31.2 \\
\hline Chloroform extract & $>500$ & $>500$ & $>500$ & $>500$ \\
\hline Aqueous extract & 500 & 62.5 & 62.5 & 15.6 \\
\hline Ethyl acetate extract & $>500$ & $>500$ & $>500$ & $>500$ \\
\hline n-Butanol extract & 500 & 31.2 & 62.5 & 31.2 \\
\hline Aether & $>500$ & $>500$ & $>500$ & $>500$ \\
\hline Gentamicin sulfate & 15.6 & 15.6 & 31.2 & 31.2 \\
\hline
\end{tabular}

showed resistance for three extracts $(\mathrm{MIC} \geq 500 \mu \mathrm{g} / \mathrm{ml})$, while T. rubrum and T. mentagrophytes were also sensitive fungus to the $n$-butanol extract $(\mathrm{MIC}=62.5$ and $31.2 \mu \mathrm{g} / \mathrm{ml})$ and aqueous extract $(\mathrm{MIC}=31.2 \mu \mathrm{g} / \mathrm{ml}) . E$. floccosum and $C$. albicans were inhibited by high concentrations of aqueous and ethanol extracts (MIC $=125$ and $62.5 \mu \mathrm{g} / \mathrm{ml})$.

The ZOI of the fermentation supernatant from puffball exhibited strong activity against test microorganisms in Table 2. Regarding antifungal activity, the strongest antifungal activity was observed using the fermentation supernatant from puffball with the ZOI value of $29.01 \pm 2.17 \mathrm{~mm}$, while the strongest antibacteria activity was the ZOI value of $35.02 \pm 2.03 \mathrm{~mm}$. The standard drug terbinafine achieved the antifungal activity against T. rubrum $(\mathrm{MIC}=31.2 \mu \mathrm{g} / \mathrm{ml}, \mathrm{ZOI}=26.09 \pm 3.06 \mathrm{~mm})$, and gentamicin sulfate achieved the highest antibacteria activity against $B$. subtilis ( $\mathrm{MIC}=15.6 \mu \mathrm{g} / \mathrm{ml}$, $\mathrm{ZOI}=43.19 \pm 0.98 \mathrm{~mm}$ ).

Due to the resistance of pathogens soon developing against current drugs, it is important to questing for more effective and safer antimicrobial therapies. Natural product being reservoirs of various types of bioactive molecules are target of extensive research worldwide. In the present work, many extracts and fermentation of puffball were subjected to antimicrobial study against a number of pathogenic microorganism.

Extracts and fermentation of puffball showed antimicrobial activity in a dose-dependent manner against the test microorganisms. T. rubrum, T. mentagrophytes, $P$. aeruginosa, and $S$. aureus were the most sensitive microorganisms to the fermentation of puffball $(\mathrm{MIC}=31.2)$, while the strongest activity was demonstrated against P. aeruginosa (MIC $=15.6 \mu \mathrm{g} / \mathrm{ml}$ ) using the aqueous extract. Besides, fermentation and extracts of puffball showed better toxicity against T. rubrum, ZOI of fermentation supernatant, ethanol, aqueous and n-butanol were about 29.01, 10.03, 15.08 and $18.22 \mathrm{~mm}$ respectively, better antibacterial activity against $S$. aureus with ZOI of fermentation supernatant, aqueous, n-butanol and ethanol being about 35.02, 22.28, 18.11 and $12.02 \mathrm{~mm}$ respectively in Table 2. Notably, fermentation of puffball showed effective against bacteria and fungus. Antifungal and anti-bacteria compounds of puffball appeared in polar solvents and are of hydrophilic nature. This may provide a lead for an antibiotic for pathogen. In general, the fermentation supernatant and more polar extracts were better antimicrobial agents than less polar counterparts. The fermentation displayed especially notable antimicrobial efficacy, this may be due to the spore 
Table 2 ZOI values of fermentation supernatant and extracts of puffball

\begin{tabular}{|c|c|c|c|c|}
\hline \multirow[t]{3}{*}{ Extracts/fractions of puffball } & \multicolumn{4}{|c|}{ Zone of inhibition $(\mathrm{mm})$} \\
\hline & \multicolumn{4}{|l|}{ Fungus } \\
\hline & T. rubrum & T. mentagrophytes & E. floccosum & C. albicans \\
\hline Fermentation supernatant & $29.01 \pm 2.17$ & $21.02 \pm 2.05$ & $12.03 \pm 1.14$ & $8.03 \pm 1.02$ \\
\hline Ethanol extract & $10.03 \pm 2.02$ & $8.02 \pm 1.12$ & $0.00 \pm 0.00$ & $5.81 \pm 0.35$ \\
\hline Chloroform extract & $0.00 \pm 0.00$ & $0.00 \pm 0.00$ & $0.00 \pm 0.00$ & $0.00 \pm 0.00$ \\
\hline Aqueous extract & $15.08 \pm 1.05$ & $17.28 \pm 1.67$ & $10.02 \pm 1.21$ & $11.36 \pm 1.33$ \\
\hline Ethyl acetate extract & $0.00 \pm 0.00$ & $0.00 \pm 0.00$ & $0.00 \pm 0.00$ & $0.00 \pm 0.00$ \\
\hline n-Butanol extract & $18.22 \pm 3.06$ & $15.65 \pm 2.16$ & $17.12 \pm 2.14$ & $12.36 \pm 1.89$ \\
\hline Aether & $0.00 \pm 0.00$ & $0.00 \pm 0.00$ & $0.00 \pm 0.00$ & $0.00 \pm 0.00$ \\
\hline Terbinafine & $26.09 \pm 3.06$ & $25.04 \pm 2.13$ & $34.12 \pm 3.02$ & $38.41 \pm 2.25$ \\
\hline \multirow[t]{3}{*}{ Extracts/fractions of puffball } & \multicolumn{4}{|c|}{ Zone of inhibition (mm) } \\
\hline & \multicolumn{4}{|l|}{ Bacteria } \\
\hline & B. subtilis & S. aureus & E. coli & P. aeruginosa \\
\hline Fermentation supernatant & $8.01 \pm 1.12$ & $35.02 \pm 2.03$ & $15.03 \pm 1.35$ & $28.01 \pm 1.59$ \\
\hline Ethanol extract & $0.00 \pm 0.00$ & $12.02 \pm 1.12$ & $6.03 \pm 1.32$ & $6.69 \pm 1.79$ \\
\hline Chloroform extract & $0.00 \pm 0.00$ & $0.00 \pm 0.00$ & $0.00 \pm 0.00$ & $0.00 \pm 0.00$ \\
\hline Aqueous extract & $12.08 \pm 1.38$ & $22.28 \pm 1.12$ & $3.02 \pm 0.92$ & $15.22 \pm 1.13$ \\
\hline Ethyl acetate extract & $0.00 \pm 0.00$ & $0.00 \pm 0.00$ & $0.00 \pm 0.00$ & $0.00 \pm 0.00$ \\
\hline n-Butanol extract & $0.00 \pm 0.00$ & $18.11 \pm 1.02$ & $16.32 \pm 0.97$ & $17.35 \pm 1.33$ \\
\hline Aether & $0.00 \pm 0.00$ & $0.00 \pm 0.00$ & $0.00 \pm 0.00$ & $0.00 \pm 0.00$ \\
\hline Gentamicin sulfate & $43.19 \pm 0.98$ & $31.03 \pm 1.76$ & $28.16 \pm 2.06$ & $32.12 \pm 2.03$ \\
\hline
\end{tabular}

The date are mean \pm SD of three repeats

germination and the active substances are liberated by rupture of spore or the major secondary metabolites were released. T. rubrum and S. aureus were the most susceptible. Further investigation into this fraction has great prospects to yield exploitable natural products for future drugs.

\section{Identification of active principle using liquid chromatography-mass spectrometry (LC-MS) analysis}

As stated above, based on Chinese Pharmacopoeia puffball has not been reported to have the antifungal activity. In a preliminary set of MIC and ZOI experiments, fermentation of puffball show best antifungal activity, so it is important to separate antifungal activity substance from puffball fermentation supernatant. However, in most cases, the base peak was broad with a low peak purity and the separation of these compounds with satisfactory resolution was not achieved. Besides that, antitinea activity maybe due to synergistic effects of different substance. The separation of purified substance is a very difficult task. Thus, we decided to validate an HPLC/ UV method to determine the total content of antifungal activity and LC/MS spectra method to determine characteristic $[\mathrm{M}+\mathrm{H}]$ ion $\mathrm{m} / \mathrm{z}$.
Puffball was collected in the same place in Jishui county, Jiangxi province and showed similar antifungal activities. Through contrast test, antifungal activity of puffball fermentation supernatant was done. Standard PDB medium (without puffball) was set as blank control. These supernatants were analyzed by LC-MS. Puffball and blank control presented different chromatographic profile. The chromatogram of puffball revealed the presence of two main peaks F1 (9.69 min) and F2 (10.34 min) while blank control without these peaks. The whole process is represented in the chromatograms shown in Fig. 1.

The characteristic peaks of fermentation were collected by preparation chromatographic for further studies. This compound was identified by comparison of HPLC retention time with blank control (standard PDB medium).

The difference is the characteristic peaks P1 and P2 inside the red circle between HPLC chromatograms of A and $\mathrm{B}$, the component in P1 and P2 was named as PBR-1 and PBR-2, then we collected the compound PBR-1 and PBR-2, the same was for standard PDB medium (retention time from 8 to $12.5 \mathrm{~min}$ ), antifungal activity test of the compound PBR-1 and PBR-2 was done. Test microorganisms were T. rubrum and T. mentagrophytes. Test 


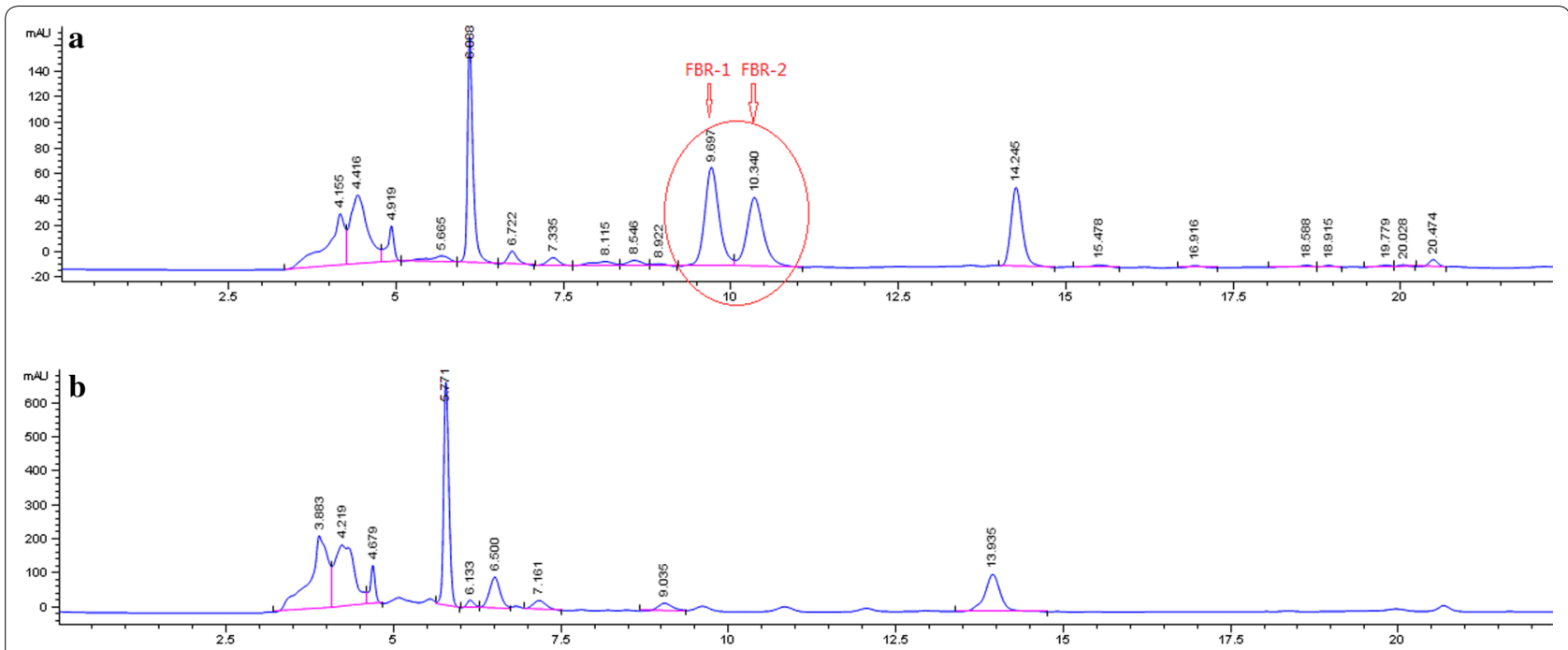

Fig. 1 HPLC chromatograms of $\mathbf{a}$ the fermentation supernatant of puffball and $\mathbf{b}$ the blank control (PDB)

method was ZOI (zone of inhibition). The test results are as follows.

\section{Antifungal activity test of characteristic peak of puffball}

Through ZOI test, we verified the antifungal activity of the compound PBR-1 and PBR-2 and PDB medium (retention time from $8 \mathrm{~min}$ to $12.5 \mathrm{~min}$ ), the activity of antifungal was showed in Fig. 2. The red circle indicates the size of ZOI. The results showed the inhibition concentration is $50 \mu \mathrm{g} / \mathrm{ml}$ and the ZOI of T. rubrum and T. mentagrophytes are 34 and $27 \mathrm{~mm}$ respectively. The results showed in Table 3.

Minimum inhibitory concentration (MIC) was carried out to determine the active concentration of the compound PBR-1 and PBR-2 that inhibited the growth of tested microorganism. MIC of the compound PBR-1 and PBR-2 against pathogenic microbes T. Rubrum and T. mentagrophytes was $15.6 \mu \mathrm{g} / \mathrm{ml}$ (Table 3). Notably, the compound PBR-1 and PBR-2 showed better antifungal activity than positive control (terbinafine hydrochloride) and fermentation of puffball. The compound PBR-1 and PBR-2 provide a lead result for antifungal activity.

The compound PBR-1 and PBR-2 of puffball were the most abundant antifungal activity bioactive fractions. The following molecular weight were identified based on the UV spectrum, mass spectra and fragmentation patterns.

\section{Purification and identification of the bioactive metabolite}

The compound PBR-1 and PBR-2 were subjected to LCQTOF-MS/MS analysis in positive mode ionizations. The MS of bioactive F1 in positive mode revealed a peak of $\mathrm{m} / \mathrm{z} 353(\mathrm{M}+\mathrm{H})$, while $\mathrm{F} 2$ in positive mode revealed a peak of $\mathrm{m} / \mathrm{z} 353(\mathrm{M}+\mathrm{H})$ and a peak of $\mathrm{m} / \mathrm{z} 413(\mathrm{M}+\mathrm{H})$ (Fig. 3). The MS/MS of 353 resulted in formation of fragments with $\mathrm{m} / \mathrm{z} 191,217,279,299$. The MS/MS of 413 resulted in formation of fragments with $\mathrm{m} / \mathrm{z} 375,381$, 399, 411, (Fig. 3). According to mass spectra and its fragmentation pattern corresponded to bioactive fractions which have molecular mass of 353 and 413 Da (Klyba et al. 2014; Vukics et al. 2008). Machining with molecular bank, molecular formula of 353 and $413 \mathrm{Da}$ are $\mathrm{C}_{21} \mathrm{H}_{36} \mathrm{O}_{4}$ (352.49) and $\mathrm{C}_{24} \mathrm{H}_{44} \mathrm{O}_{5}$ (412.58) respectively.

Fermentation supernatant of puffball has high activity against fungus, we conclude that water soluble antibacterial substances contain a lot of hydroxyl groups, based on Chinese pharmacopoeia, biological activity include steroidal, sesquiterpenes, flavonoids, alkaloids, puffball polysaccharide, fatty acid, proteins, amino acid and so on in puffball. It need to further study to identify molecular structure of antifungal properties from puffball and modify it to improve it's anti-microbiological activity.

\section{Discussion}

Tinea pedis fungal infection pathogens mainly include T. rubrum, T. mentagrophytes and C. albicans, about $70 \%$ of clinical fungal infection pathogens is T. rubrum, $15 \%$ of clinical fungal infection pathogens is T. mentagrophytes, C. albicans and other bacterials share $15 \%$. Puffball are widespread in natural environments and puffball species have been and continue to be extensively screened for their potential for producing useful natural products (Nedelcheva et al. 2007). Previously many researchers have reported that puffball produced antibacteria activity (Canli et al. 2016; Ng et al. 2003). The present study showed that fermentation supernatant of 


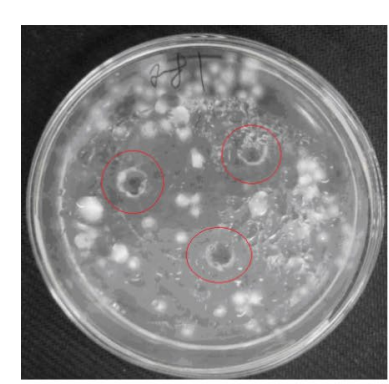

(1)

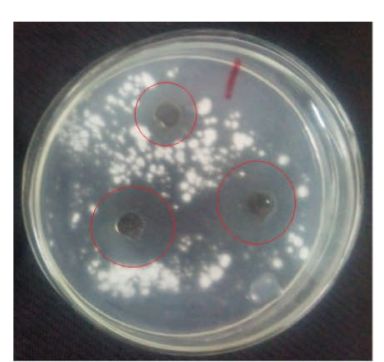

(3)

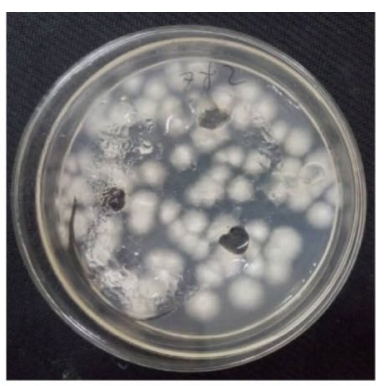

(2)

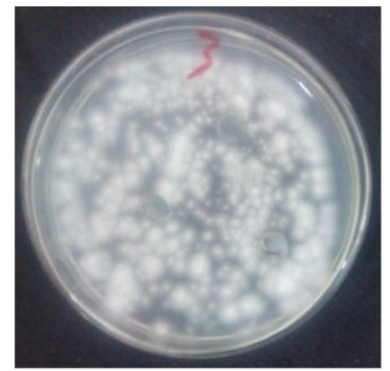

(4)

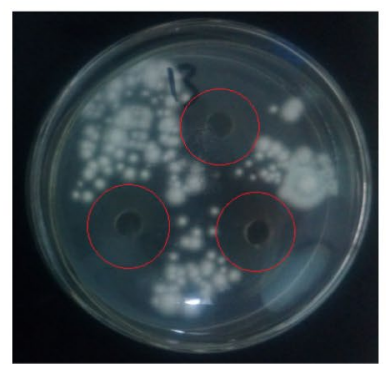

(5)

Fig. 2 Antifungal activity of fermentation and aqueous extracts. (1) Contrast 1 is antifungal test of terbinafine, (2) contrast 2 is antifungal test of distilled water, (3) antifungal test of fermentation of puffball, (4) antifungal test of PDB medium, (retention time from 8 to $12.5 \mathrm{~min}$ ), (5) antifungal activity of compound FBR-1 and FBR-2

puffball(Bovistella radicata) had potent antifungal and antibacterial activity with MIC value of $31.2 \mu \mathrm{g} / \mathrm{ml}$, Maximum zone of inhibition (ZOI) was observed against $T$. rubrum $(29.01 \mathrm{~mm})$, T. mentagrophytes $(21.02 \mathrm{~mm}), E$. floccosum $(12.03 \mathrm{~mm})$, C. albicans $(8.03 \mathrm{~mm})$, B. subtilis $(8.01 \mathrm{~mm})$, S. aureus $(35.02 \mathrm{~mm})$, E. coli $(15.03 \mathrm{~mm}), P$. aeruginosa $(28.01 \mathrm{~mm})$. The antifungal activity of puffball may be attributed to an array of secondary metabolites by its spore germination, then the active substances are liberated by rupture of spore or the major secondary metabolites were produced just like steroid saponins, sesquiterpenes, flavonoids, alkaloids, puffball polysaccharide, fatty acids, amino acid, proteins and peptides and so on (Cantrell et al. 1999; Lam et al. 2001; Kamo et al. 2006). The present study revealed that puffball isolated
Table $3 \mathrm{MIC} / \mathrm{ZO}$ values of compound PBR-1 and PBR-2 from puffball against pathogen

\begin{tabular}{llll}
\hline Test items & & T. rubrum & T. mentagrophytes \\
\hline PBR-1 and PBR-2 & MIC $(\mu \mathrm{g} / \mathrm{ml})$ & 15.6 & 15.6 \\
& $\mathrm{ZOI}(\mathrm{mm})$ & 34 & 27 \\
Terbinafine hydrochloride & $\mathrm{MIC}(\mu \mathrm{g} / \mathrm{ml})$ & 31.2 & 15.6 \\
& $\mathrm{ZOI}(\mathrm{mm})$ & 26 & 25 \\
\hline
\end{tabular}

from JiangXi province showed good antimicrobial activity against tested microbes in preliminary screening.

Steroid saponins have been reported to possess a wide range of biological activities including antibacterial (Gan et al. 2014), antifungal (Wang et al. 2015), immuno inhibitory (Nunez 1988). The bioactivity of steroidal is due to the presence of a steroid nucleus in its structure, which can be damage to the membrane and leakage of cellular materials, ultimately leading to bacteria and fungus death (Moulin-Traffort et al. 1998). So steroidal saponins maybe also have a significant role against the growth of T. rubrum and T. mentagrophytes. The role of the isolated steroidal compounds on persons' health should be further investigated to understand its action in vivo. Sesquiterpene lactones possessed very high antifungal activity (Vajs et al. 1999). The biological activity of sesquiterpene lactones is generally attributed to the alkylating property of the $\alpha$-methylene- $\gamma$-lactone moiety, and the presence of other alkylating sites (epoxides and conjugated carbonyl groups) may enhance their biological activities. Moreover, their lipophilicity seems to play an important role in antifungal activity. Since the chemical composition of the fungal cells walls is highly lipophilic, they generally represent strong barriers for the penetration of hydrophilic compounds, and the transport of polar compounds through the outer lipid layer of fungi is retarded (Skaltsa et al. 2000). Flavonoids can complex with extracellular soluble proteins and bacterial cell walls, maybe it is the reason which Flavonoids possess antimicrobial activity (Hossain et al. 2013), more lipophilic flavonoids may also disrupt microbial membranes (Ghanbari et al. 2012).

The main mechanism of the anti-microorganism of polysaccharide is to suppress signal recognition mechanism of the microorganism, which may be related with microorganism growth and mutual recognition (Schmidtchen and Malmsten 2015). Alkaloids isolated from plant are commonly found to have antimicrobial properties (Jiang et al. 2016). Berberine and hormone are important representatives of the alkaloid group. The mechanism of action of highly aromatic planar quaternary alkaloids such as berberine and harmane is attributed to their ability to intercalate with DNA (Jiang et al. 2011). 


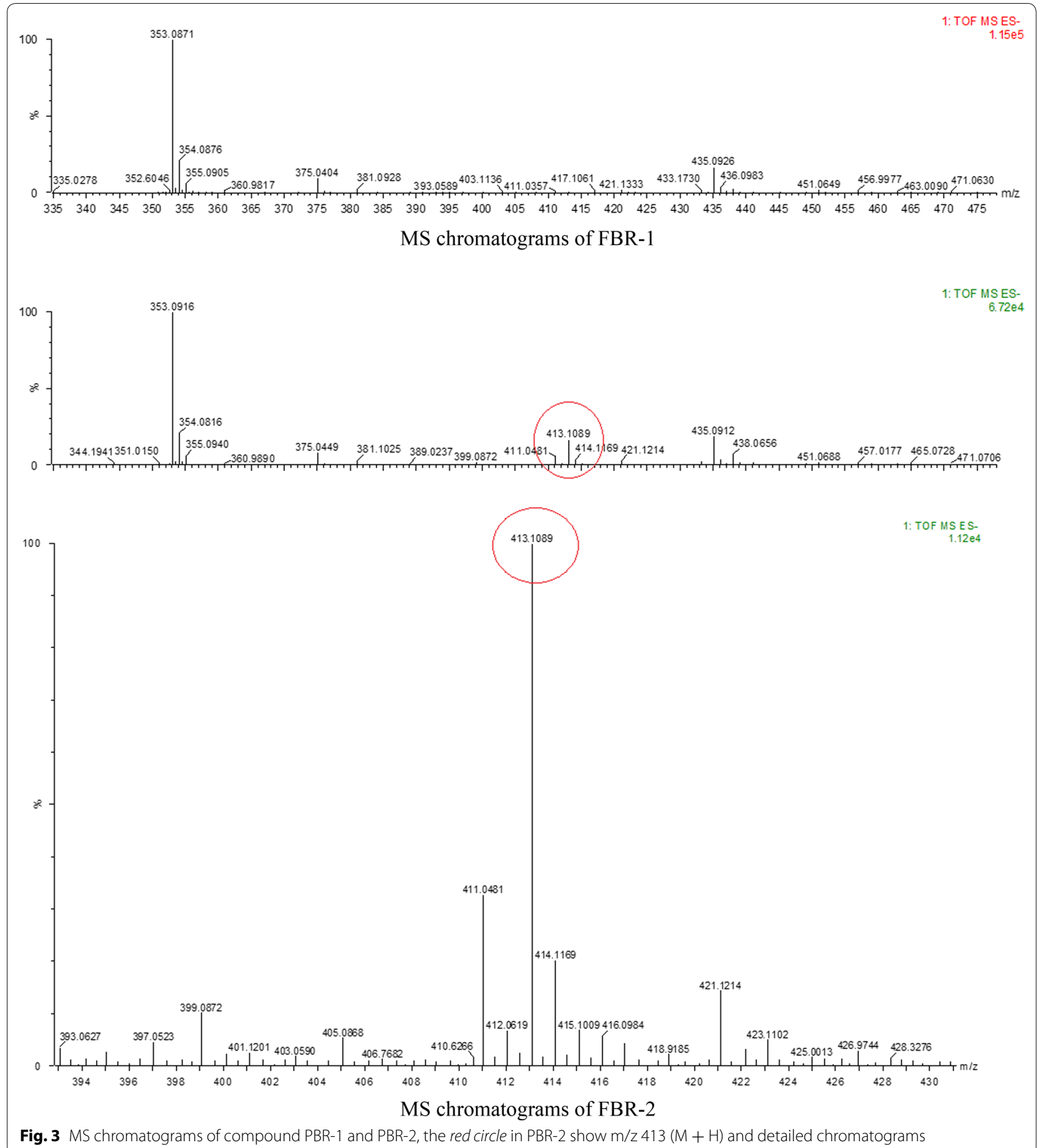

The chemical profile was analyzed in fermentation supernatant of puffball; it revealed the diversity of secondary metabolites. In future we may isolate the active molecules from the fermentation and use it as drugs for the control of microbes causing infectious diseases.
Puffball(Bovistella radicata) from Jiangxi province showed antibacterial and antifungal activity in contrast to the rest of puffball which had no detectable antifungal activity. Based on the Pharmacopeia, the main antimicroorganism function of puffball is anti-S. aureus 
and $P$. aeruginosa, the different results concerning the anti-microorganism activity of puffball might be due to different geographic sources of the material used, different types of strains used, and different assay methods (Awadh et al. 2003).

Since puffball demonstrated activity against the most prevalent microorganism, the use of puffball as anti-tinea pedis is validated, scientifically supported by the results obtained in this work.

\begin{abstract}
Abbreviations
UPLC: ultra-performance liquid chromatography; UV: ultraviolet; MS: mass; TOF: time of flight; ZOI: zones of inhibition; MIC: minimum inhibitory concentrations; PBR: peak of Bovistella radicata; PDA: potato dextrose agar; PDB: potato dextrose broth.
\end{abstract}

\section{Authors' contributions}

YY collected the data, created figures, and drafted the manuscript with the guidance of corresponding author (QZ). Co-authors helped to draft the manuscript. All authors read and approved the final manuscript.

\section{Acknowledgements}

The author wish to thank Dr. Kun liu and Qinghua Zeng (from School of Food Science and Engineering, Hefei University of Technology, Anhui, China) for help in experiment.

\section{Competing interests}

The authors declare that they have no competing interests.

\section{Availability of data and materials}

All data are fully available without restriction.

\section{Consent for publication}

This manuscript does not contain any individual person's data.

\section{Ethics approval and consent to participate}

No animal or human subjects were used in this work.

\section{Funding}

This study was funded by the National Natural Science Foundation of China (Grant Nos. 31371844; 31071556) and Science and Technology Department of Anhui province, PR of China (Grant No. 1301032155).

\section{Publisher's Note}

Springer Nature remains neutral with regard to jurisdictional claims in published maps and institutional affiliations.

Received: 20 April 2017 Accepted: 10 May 2017

Published online: 19 May 2017

\section{References}

Awadh Ali NA, Mothana RA, Lesnau A, Pilgrim H, Lindequist U (2003) Antiviral activity of Inonotus hispidus. Fitoterapia 74:483-486

Bourdeau P, Marchand A, Etoré F (2004) P-17 In vitro activity of posaconazole and other antifungals against Malassezia pachydermatis isolated from dogs. Vet Dermatol 15:45-46

Canli K, Altuner EM, Akata I, Turkmen Y, Uzek U (2016) In vitro antimicrobia screening of Lycoperdon lividium and determination of the ethanol extract composition by gas chromatography/mass spectrometry. Bangl. J. Pharmacol 2:391-394

Cantrell CL, Rajab MS, Franzblau SG, Fronczek FR, Fischer NH (1999) Antimycobacterial ergosterol-5, 8-endoperoxide from Ajuga remota. Planta Med $65: 732-734$
Cornaglia G (2009) Fighting infections due to multidrug-resistant Gram-positive pathogens. Clin Microbiol Infect 15:209-211

Cotter G, Kavanagh K (2000) Adherence mechanisms of Candida albicans. Br J Biomed Sci 57:241-249

Dharajiya D, Patel P, Moitra N (2015) Antibacterial activity of Emblica officinalis (Gaertn.) Fruits and Vitex negundo (L.) Leaves. Curr Trends Biotechnol Pharm. 9:357-368

Djeridane A, Djeridane Y, Ammar-Khodja A (2006) Epidemiological and aetiological study on tinea pedis and onychomycosis in Algeria. Mycoses 49:190-196

Erbagci Z, Tuncel A, Zer Y, Balci I (2005) A prospective epidemiologic survey on the prevalence of onychomycosis and dermatophytosis in male boarding school residents. Mycopathologia 159:347-352

Gan C, Cui J, Su S, Lin Q, Jia L, Fan L, Huang Y (2014) Synthesis and antiproliferative activity of some steroidal thiosemicarbazones, semicarbazones and hydrozones. Steroids 87:99-107

Geetha R, Sathian CT, Prasad V, Gleeja VL (2015) Efficacy of purified antimicrobial peptides from lactic acid bacteria against bovine mastitis pathogen. Asian J Dairy Food Res 34:259-264

Ghanbari R, Anwar F, Alkharfy KM, Gilani AH, Saari N (2012) Valuable nutrients and functional bioactives in different parts of olive (Olea europaea L.) —a review. Int J Mol Sci 13:3291-3340

Hopper S (1992) Standard methods for the examination of dairy products, 11th ed. American Public Health Association, Washington. 11:940-941

Hossain MA, AL-Raqmi KA, AL-Mijizy ZH, Weli AM, Al-Riyami Q, Mohammad AH, Khulood AS (2013) Study of total phenol, flavonoids contents and phytochemical screening of various leaves crude extracts of locally grown Thymus vulgaris. Asian Pacific J Trop Biomed 3:705-710

Jiang J, Eliaz I, Sliva D (2011) Suppression of growth and invasive behavior of human prostate cancer cells by ProstaCaid: mechanism of activity. Int J Oncol 38:1675-1682

Jiang QW, Chen MW, Cheng KJ, Yu PZ, Wei X, Shi Z (2016) Therapeutic potential of steroidal alkaloids in cancer and other diseases. Med Res Rev 36:119-143

Kamo T, Kashiwabara M, Tanaka K, Tanaka K, Ando S, Shibata H, Hirota M (2006) Plant growth inhibitory activity of azo-and azoxyformamides from Calvatia craniiformis and Lycoperdon hiemale. Nat Prod Res 20:507-510

Klyba L, Nedolya N, Tarasova O, Sanzheeva E (2014) Mass spectra of new heterocycles Main fragmentation pathways of the molecular ions of 5-methylsulfanyl-1-vinyl-1 H-pyrrol-2-amines under electron impact and chemical ionization. Russ J Org Chem 50:35-44

Koltin Y, Hitchcock CA (1997) The search for new triazole antifungal agents. Curr Opin Chem Biol 1:176-182

Lam YW, Ng TB, Wang HX (2001) Antiproliferative and antimitogenic activities in a peptide from puffball mushroom Calvatia caelata. Biochem Biophys Res Commun 289:744-749

Moulin-Traffort J, Favel A, Elias R, Regli P (1998) Study of the action of alphahederin on the ultrastructure of Candida albicans. Mycoses 41:411-416

Nedelcheva D, Antonova D, Tsvetkova S, Marekov I, Momchilova S, NikolovaDamyanova B, Gyosheva M (2007) TLC and GC-MS probes into the fatty acid composition of some Lycoperdaceae mushrooms. J Liq Chromatogr Relat T 30:2717-2727

Negi PS, Anandharamakrishnan C, Jayaprakasha GK (2003) Antibacterial activity of Aristolochia bracteata root extracts. J Med Food 6:401-403

$\mathrm{Ng}$ TB, Ying WL, Wang H (2003) Calcaelin, a new protein with translationinhibiting, antiproliferative and antimitogenic activities from the mosaic puffball mushroom Calvatia caelata. Planta Med 69:212-217

Novaković AR, Karaman MA, Matavulj MN, Pejin BM, Belović MM, Radusin TI, Ilić NM (2015) An insight into in vitro bioactivity of wild-growing puffball species Lycoperdon perlatum (Pers) 1796. Food Feed Res 42:51-58

Nunez EA (1988) Modulation of cell-mediated immune response by steroids and free fatty acids in AIDS patients: a critical survey. Tumour Biol 9:225-232

Petar R, Ivica D, Jelena T, Tanja B, Irena V, Dušanka M, Slaviša S (2016) Antimicrobial activity of serbian propolis evaluated by means of MIC, HPTLC. Bioautography Chemom Plos One. 11:1-15

Schmidtchen A, Malmsten M (2015) (Lipo) polysaccharide interactions of antimicrobial peptides. J Colloid Interface Sci 449:136-142

Sen A, Gurbuz B, Gurer U, Bulut G, Bitis L (2014) Flavonoids and biological activities of Centaurea stenolepis. Chem Nat Compd 50:128-129 
Skaltsa H, Lazari D, Panagouleas C, Georgiadou E, Garcia B, Sokovic M (2000) Sesquiterpene lactones from Centaurea thessala and Centaurea attica. Antifung Act Phytochem 55:903-908

Subissi A, Monti D, Togni G, Mailland F (2010) Ciclopirox recent nonclinical and clinical data relevant to its use as a topical antimycotic agent. Drugs. 70:2133-2152

Tian S, Shi Y, Zhou X, Ge L, Upur H (2011) Total polyphenolic (flavonoids) content and antioxidant capacity of different Ziziphora clinopodioides Lam. Extr Pharmacogn Mag 7:65-68

Vajs V, Todorović N, Ristić M, Tesević V, Todorović B, Janaćković P, Marin P, Milosavljević $S$ (1999) Guaianolides from Centaurea nicolai: antifungal activity. Phytochemistry 52:383-386

Vukics V, Kery A, Bonn GK, Guttman A (2008) Major flavonoid components of heartsease (Viola tricolor L.) and their antioxidant activities. Anal Bioanal Chem 390:1917-1925

Wang AR, Song HC, An HM, Huang Q, Luo X, Dong JY (2015) Secondary metabolites of plants from the genus chloranthus: chemistry and biological activities. Chem Biodivers 12:451-473

Xiao JC, Chen HM, Dian K (2016) Qualitatively and quantitatively investigating the regulation of intestinal microbiota on the metabolism of panax notoginseng saponins. J Ethnopharmacol 194:324-336
Zampini IC, Cuello S, Alberto MR, Ordoñez RM, D’Almeida Solorzano ER, Isla MI (2009) Antimicrobial activity of selected plant species from "the Argentine Puna" against sensitive and multi-resistant bacteria. J Ethnopharmacol 124:499-505

Zhang BL, Fan CQ, Dong L, Wang FD, Yue JM (2011) Structural modification of a specific antimicrobial lead against Helicobacter pylori discovered from traditional Chinese medicine and a structure-activity relationship study. Eur J Med Chem 45:5258-5264

Zhang J, Zhu X, Luo F, Sun C, Huang J, Li X, Chen K (2012) Separation and purification of neohesperidin from the albedo of Citrus reticulata $\mathrm{CV}$. Suavissima by combination of macroporous resin and high-speed counter-current chromatography. J Sep Sci 35:128-136

Zuo GY, Han ZQ, Hao XY (2014) Synergy of aminoglycoside antibiotics by 3-Benzylchroman derivatives from the Chinese drug Caesalpinia sappan against clinical methicillin-resistant Staphylococcus aureus (MRSA). Phytomedicine 21(7):936-941

Zuo GY, Wang CJ, Han J, Li YQ, Wang GC (2016) Synergism of coumarins from the Chinese drug Zanthoxylum nitidum with antibacterial agents against methicillin-resistant Staphylococcus aureus (MRSA). Phytomedicine 23(14):1814-1820

\section{Submit your manuscript to a SpringerOpen ${ }^{\circ}$ journal and benefit from:}

- Convenient online submission

- Rigorous peer review

- Immediate publication on acceptance

- Open access: articles freely available online

- High visibility within the field

- Retaining the copyright to your article 